\title{
Diagnosis of hepatocellular carcinoma using a novel anti-glycocholic acid monoclonal antibody-based method
}

\author{
MIAO WU $^{1 *}$, SONGHUI ZHAI $^{2 *}$, JULIA GAO $^{1}$, DAPENG WEI $^{1}$, \\ JIANXIN XUE ${ }^{3}$, YUXI ZHOU ${ }^{4}$, NAN LI ${ }^{1}$ and LIJUAN HU ${ }^{1}$ \\ ${ }^{1}$ Department of Immunology, West China School of Basic Medical Sciences and Forensic Medicine; ${ }^{2}$ Department of \\ Pediatrics, West China Second University Hospital; ${ }^{3}$ Department of Thoracic Oncology, Cancer Center, \\ West China Hospital, Sichuan University, Chengdu, Sichuan 610041; ${ }^{4}$ Department of Pharmacy, \\ Mianyang People's Hospital, Mianyang, Sichuan 621000, P.R. China
}

Received March 28, 2018; Accepted December 5, 2018

DOI: $10.3892 / \mathrm{ol} .2019 .9943$

\begin{abstract}
Glycocholic acid (GCA) is a novel identified biomarker for hepatocellular carcinoma (HCC). However, clinical pathological study of GCA has not been extensive due to the limited availability of anti-GCA monoclonal antibodies (mAbs) and restricted detection methods. In the present study, using human GCA conjugated with bovine serum albumin as the immunogen to immunize BALB/c mice, a novel anti-GCA $\mathrm{mAb}$ was generated and characterized. The isotypes of heavy chain and light chain of anti-GCA mAb were examined to be $\operatorname{IgG} 2 \mathrm{a}$ and $\kappa$, respectively, with a high affinity constant $\left(2.6 \times 10^{8} \mathrm{~mol} / \mathrm{l}\right)$. The anti-GCA mAb binds GCA with high specificity and sensitivity, and the $50 \%$ inhibitory rate was $77.09 \mathrm{ng} / \mathrm{ml}$. The present study also established a rapid, sensitive and efficient indirect competitive ELISA analysis using this anti-GCA mAb to detect the level of GCA produced by different HCC cell lines. Therefore, the present study may successfully develop a novel method for early HCC diagnosis, and also provide insights for further research and treatment of HCC.
\end{abstract}

\section{Introduction}

Hepatocellular carcinoma (HCC) is one of the most common types of cancer globally, and the third highest cause of cancer-associated mortality globally, according to 2018

Correspondence to: Dr Lijuan Hu or Professor Nan Li, Department of Immunology, West China School of Basic Medical Sciences and Forensic Medicine, Sichuan University, 17 Renmin South Road, Chengdu, Sichuan 610041, P.R. China

E-mail: hulijuan@scu.edu.cn

E-mail: nanli@scu.edu.cn

*Contributed equally

Key words: glycocholic acid, monoclonal antibody, hepatocellular carcinoma, indirect competitive enzyme-linked immunoassay statistics (1). The high mortality rate may be partially attributed to the fact that $\sim 80 \%$ of patients with novel diagnosed HCC have already been diagnosed with advanced liver disease and hepatic cirrhosis (2-4). Altekruse et al (5) reported that $>60 \%$ of patients were diagnosed with late-stage HCC following metastasis, resulting in a $<16 \%$ overall 5 -year survival rate (6). However, if an appropriate diagnosis and treatment can be used in the early stage of HCC, the 5-year survival rate of patients may increase by $75 \%$ (7). Therefore, an effective way to detect $\mathrm{HCC}$ at early stage would improve the outcomes for patients significantly. At present, the diagnosis of HCC remains largely dependent on invasive biopsy, imaging methods, including magnetic resonance imaging, 18-fluoro-deoxyglucose positron emission tomography/computerized topography and serum $\alpha$-fetoprotein testing $(1,8)$. The limited sensitivity and specificity of these methods result in poor quality and a low diagnosis rate. Therefore, the identification of biomarkers with a higher sensitivity and specificity is vital for HCC diagnosis, particulalry for earlier stages of HCC (9). A previous study reported that urine and serum contain a lot of metabolic information that may be altered underlying HCC, which may be used as new biomarkers for HCC diagnosis (10). Additionally, the level of glycocholic acid (GCA) in patients with HCC is significantly increased, compared with healthy individuals (11). GCA has been identified as a specific and sensitive biomarker for HCC in urine and serum $(12,13)$.

GCA, a secondary bile acid and one of the main components of bile acids, is formed by the conjugation of cholic acid and glycine, which assists in the digestion and the absorption of fat in food, in addition to being located in the bile as a sodium salt (14). Numerous studies reported that GCA may serve as a superior clinical marker to detect liver diseases, compared with the traditional markers, including serum alpha fetoprotein, blood enzymology and metabolomics $(13,15,16)$. Analysis of GCA in combination with other diagnostic indicators provides a more sensitive background for the diagnosis, treatment and prognosis of liver diseases (17). Additionally, the level of GCA is also a vital diagnostic indicator for various biliary system diseases, including intrahepatic cholestasis and alcoholic liver injury (18). Currently, a number of methods have been reported for the analysis of GCA, including liquid 
chromatography-mass spectrometry (19), ultra-performance liquid chromatography-quadrupole time-of-flight-high-definition mass spectrometry (12), liquid chromatography-tandem mass spectrometry (20) and macromolecular crowding agents-assisted imprinted polymers (13). However, these methods come with a high cost as they require a well-equipped laboratory and well-trained professionals $(19,20)$. Therefore, there is a great demand for developing a more economical, reliable and rapid method to detect GCA.

In the present study, a novel anti-GCA monoclonal antibody (mAb) was generated, in which low $50 \%$ inhibitory rate $\left(\mathrm{IC}_{50}\right)$, high specificity and sensitivity for GCA binding were reached. Furthermore, by this novel development of $\mathrm{mAb}$, an effective indirect competitive ELISA method (icELISA) has been established to detect GCA. Therefore, a simple, rapid and efficient method was successfully developed to detect GCA for the diagnosis of early-stage $\mathrm{HCC}$, in addition to providing novel insights for further research and treatment of HCC.

\section{Materials and methods}

Immunogen preparation. Human GCA hydrate (C26H43NO6. $\mathrm{xH}_{2} \mathrm{O}$ ) synthesized by Sigma-Aldrich (Merck KGaA, Darmstadt, Germany) was conjugated to the carrier protein, bovine serum albumin (BSA; BioFroxxx, Germany), by the active ester method through amide bonds $(21,22)$, using 1-ethyl-3-(3-dimethylaminopropyl) carbodiimide hydrochloride (EDC) and N-hydroxysuccinimide (NHS) as the dehydrating agents. A total of $10 \mathrm{mg} \mathrm{GCA}$ was mixed with $100 \mu 1$ 2-(morpholino) ethanesulfonic acid buffered saline (0.5 M NaCl, pH 6.0) and conjugated to BSA at the molecular ratio of 100:1 in $500 \mathrm{ml}$ conjugation buffer (PBS; $\mathrm{pH}=7.2-7.4$ ). Following incubation at room temperature for $2 \mathrm{~h}$, GCA-BSA conjugate (GCA-BSA) was purified by a desalting column and identified by $10 \%$ SDS-PAGE, and then dyed by $0.25 \%$ Coomassie Brilliant Blue R-250 (Beijing Solarbio Science \& Technology Co., Ltd., Beijing, China) for $2 \mathrm{~h}$ at $37^{\circ} \mathrm{C}(23,24)$.

Mice preparation and immunization. Five female BALB/c mice (6-8 weeks old, 20 g), purchased from Medical Animal Center of Sichuan University (Chengdu, China), were maintained in individually ventilated cages under specific pathogen free conditions, including a temperature of $24^{\circ} \mathrm{C}$, a humidity of $55 \pm 10 \%$, adequate food and water and a $12 / 12 \mathrm{~h}$ light/dark cycle. The mice immunized with immunogens at multiple sites by standard vaccination procedures. Ethical approval for the use of animals was obtained from the Research Ethics Committee of West China School of Basic Medical Sciences and Forensic Medicine, Sichuan University (Sichuan, China). All experimental procedures complied with Sichuan University Committee Guidelines on the Use of Live Animals in Research, in accordance with the National Institutes of Health Guide for the Care and Use of Laboratory Animals (25).

As previously described (26), mice were subcutaneously immunized with $100 \mu \mathrm{g}$ GCA-BSA emulsified with Freund's complete adjuvant (Sigma-Aldrich; Merck KGaA) with a volume ratio of $1: 1$. To strengthen the immune response, subcutaneous injections with the same dose and method were repeated three times within 2 months. Prior to the last injection, blood was drawn from the mouse-tail vein and the serum was isolated. The serum titers were analyzed by indirect ELISA assay. Anti-GCA mAb in mouse-tail vein serum was used as the primary antibody and a horseradish peroxidase-conjugated goat anti-mouse IgG (cat. no. ab97051; Abcam, Cambridge, UK) was used as the secondary antibody.

Hybridoma generation and screening. The mouse myeloma SP2/0 cell line was used as a fusion partner. Subsequently, 1 week prior to the fusion, SP2/0 (cat. no. NCBI 129; National Cell Bank of Iran, Pasteur Institute of Iran, Tehran, Iran) was cultured in RPMI-1640 media (Sigma-Aldrich; Merck KGaA) and $10 \%$ fetal bovine serum (FBS, Sigma-Aldrich; Merck $\mathrm{KGaA}$ ) until reaching to $>70 \%$ confluency. The feeder-layer cells were prepared from the peritoneal cavity of unimmunized BALB/c mouse 1 day prior to fusion. Following the final injection, one immunized mouse with the highest serum titer $(>1: 409,000)$ was sacrificed, and splenocytes were collected for fusion with mouse myeloma SP2/0 cells using 50\% polyethylene glycol (cat. no. PEG4000, Sigma-Aldrich; Merck $\mathrm{KGaA}$ ) at a splenocyte:myeloma cell ratio of 10:1, according to the standard procedures of hybridoma technique under sterile condition (27). Fused cells were washed with RPMI-1640 medium and distributed in 96-well plates followed by selection with hypoxanthine-aminopterin-thymidine medium (Sigma-Aldrich; Merck KGaA) to screen and obtain the positive hybridoma cells.

Cell growth and colony formations were examined daily. Colonies appeared between 5 and 10 days. Once the colony diameter reached $1 \mathrm{~mm}$, determined by Image pro plus 7.0 (Media Cybernetics, Inc., Rockville, MD, USA), the immortalized cells were screened and selected for their capability to generate an anti-GCA mAb with an ELISA, as described previously (28). A total of two 96-well microtiter plates were coated with GCA as the coating antigen with $1 \mu \mathrm{g} / \mathrm{ml}(100 \mu \mathrm{l} /$ well $)$ at $4^{\circ} \mathrm{C}$ overnight and unoccupied binding sites on the plates were blocked by $120 \mu \mathrm{l} /$ well $1 \% \mathrm{BSA}$ in PBS at $37^{\circ} \mathrm{C}$ for $1 \mathrm{~h}$. A total of $50 \mu \mathrm{l} /$ well of hybridoma supernatant was added into the plates as a primary antibody, whereas the RPMI-1640 medium was used as the negative control. The plates were subsequently incubated at $37^{\circ} \mathrm{C}$ for $1 \mathrm{~h}$. Following washing in triplicate by $0.05 \%$ Tween-20 PBS (PBST), $100 \mu \mathrm{l} /$ well of goat anti-mouse IgG conjugated with horseradish peroxidase (HRP) was added into the 96-well plate as the secondary antibody (cat. no. TA130001; OriGene Technologies, Inc., Rockville, MD, USA), and the plates were incubated at $37^{\circ} \mathrm{C}$ for $1 \mathrm{~h}$. Following washing with PBST, $100 \mu \mathrm{l} /$ well tetramethyl-benzidine (TMB; Beijing Solarbio Science \& Technology Co., Ltd.) substrate was added into the plates at $37^{\circ} \mathrm{C}$ for $15 \mathrm{~min}$. The reaction was stopped by $50 \mu \mathrm{l} /$ well of $\mathrm{H}_{2} \mathrm{SO}_{4}(2 \mathrm{~mol} / \mathrm{l})$ and optical density absorbance value (OD) was measured at wavelength of $450 \mathrm{~nm}$ with an ELISA Reader (Bio-Rad Laboratories Inc., Hercules, CA, USA). The positive clone was selected and subcloned into 96-well plates by the limiting dilution method (29) and the supernatant of the positive clone was detected with an ELISA kit, as aforementioned.

Generation, purification and detection of ascites. A total of five adult female BALB/c mice were intraperitoneally injected with sterile paraffin oil $(0.5 \mathrm{ml} / \mathrm{mouse}$; Sigma-Aldrich; Merck $\mathrm{KGaA}$ ). After 7 days, each mouse was injected peritoneally with $5 \times 10^{6}$ screened hybridoma cells. Within 10-14 days following 
the peritoneal injection, ascites were collected from the mice. The supernatant of the ascites containing anti-GCA mAb was collected by centrifugation at $19,400 \times \mathrm{g}$ for $5 \mathrm{~min}$ at $4^{\circ} \mathrm{C}$, purified by ammonium sulfate precipitation, followed by further depuration with protein-G affinity chromatography (GE Healthcare, Chicago, IL, USA) according to the manufacturer's protocols (30), and then detected by the ELISA method (26).

Affinity and isotype analysis of anti-GCA $m A b$. Affinity of anti-GCA mAb was examined by non-competitive ELISA. A 96-well plate was coated with three different concentrations of the synthesized GCA hydrate $(2.0,1.0$ and $0.5 \mathrm{mg} / \mathrm{l})$, into which the 2-fold diluted anti-GCA mAbs were added. The 96-well plate was incubated at $37^{\circ} \mathrm{C}$ for $1 \mathrm{~h}$, followed by three washes with PBST buffer to remove unbound substances. The plate was incubated with secondary antibody (goat anti-mouse IgG antibody 1:5,000; cat. no. ab97051; Abcam) at $37^{\circ} \mathrm{C}$ for $1 \mathrm{~h}$ and $\mathrm{TMB}$ was added to the plate at $37^{\circ} \mathrm{C}$ for $15 \mathrm{~min}$. The OD values at a wavelength of $450 \mathrm{~nm}$ were detected. The curve diagram was made and the affinity of the antibody was obtained as described previously (31). The curves were produced with OD values as the $y$-axis and the concentration logarithm of anti-GCA mAb based on 10 (Ige) as the $\mathrm{X}$-axis. The upper platform stage of curves was designed at $\mathrm{OD}_{100}$. Then the corresponding $\mathrm{Ab}$ concentration logarithm values at 50\% (OD50) of each curve was detected, which were termed $[\mathrm{Ab}] \mathrm{t} 1,[\mathrm{Ab}] \mathrm{t} 2$ and $[\mathrm{Ab}] \mathrm{t} 3$, respectively The affinity constant of antigen-antibody interaction was designed by the following equation: $\operatorname{Kaff}=(\mathrm{n}-1) / 2\left[\mathrm{n}\left(\mathrm{Ab}^{\prime}\right) \mathrm{t}-(\mathrm{Ab}) \mathrm{t}\right]$, where $\mathrm{n}=$ $(\mathrm{Ag}) \mathrm{t} /\left(\mathrm{Ag}^{\prime}\right) \mathrm{t},(\mathrm{Ag}) \mathrm{t}$ and $\left(\mathrm{Ag}^{\prime}\right) \mathrm{t}$ represent three different concentrations of GCA-BSA antigen, and $\left(\mathrm{Ab}^{\prime}\right) \mathrm{t}$ and $(\mathrm{Ab}) \mathrm{t}$ represent the corresponding $\mathrm{Ab}$ concentration logarithm values at $50 \%$ of each curve. The concentration ratio of the antigen was 1:2. $\mathrm{K} 1=1 / 2[2(\mathrm{Ab}) \mathrm{t} 1-(\mathrm{Ab}) \mathrm{t} 2], \mathrm{K} 2=1 / 2[2(\mathrm{Ab}) \mathrm{t} 2-(\mathrm{Ab}) \mathrm{t} 3]$ and $\mathrm{K} 3=$ $3 / 2[4(\mathrm{Ab}) \mathrm{t} 1-(\mathrm{Ab}) \mathrm{t} 3]$ when the ratio was $1: 4$. The final K-value was the average of the aforementioned three results.

The isotype of mAb was analyzed with an Antibody Isotyping kit (SouthernBiotech, Birmingham, AL, USA), according to manufacturer's protocols (32). The 96-well microtiter plates were coated by $1 \mu \mathrm{g} / \mathrm{ml}(100 \mu \mathrm{l} /$ well $)$ GCA-BSA as the coating antigen at $4^{\circ} \mathrm{C}$ overnight. The plates were subsequently blocked with $1 \%$ casein at $37^{\circ} \mathrm{C}$ for $1 \mathrm{~h}$ and washed with PBST three times. The culture supernatants of the hybridoma cell were incubated in 96 -well plates $(100 \mu \mathrm{l} /$ well) at $37^{\circ} \mathrm{C}$ for $1 \mathrm{~h}$ with gentle shaking. Following three washes with PBST buffer, AP-labeled detection antibody (dilution, 1:500, Mouse Ig Isotyping kit; SouthernBiotech, Birmingham, AL, USA) in BSA was added and incubated at $37^{\circ} \mathrm{C}$ for $1 \mathrm{~h}$. The OD of each well was measured at a wavelength of $405 \mathrm{~nm}$ following substrate addition (33).

Specificity analysis by competitive western blot analysis. BSA $(500 \mu \mathrm{g} / \mathrm{ml})$ and GCA-BSA $(500 \mu \mathrm{g} / \mathrm{ml})$ were separated by $10 \%$ SDS-PAGE and electro-transferred to a polyvinylidene fluoride membrane (PVDF) at room temperature for $1 \mathrm{~h}$. They were subsequently blocked by $10 \mathrm{mM}$ PBST containing $5 \%$ skim milk (Beijing Solarbio Science \& Technology Co., Ltd.) at room temperature for $1 \mathrm{~h}$. The PVDF membrane was cut into two identical parts. A part of the membrane was incu-

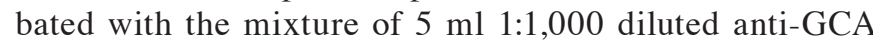

mAb plus $5 \mathrm{ml}$ PBST as the non-competitive group. Another part of membrane was incubated with the mixture of $5 \mathrm{ml}$ 1:1,000 diluted anti-GCA mAb plus $5 \mathrm{ml}$ GCA $(10 \mu \mathrm{g} / \mathrm{ml})$ as the competitive group, at room temperature for $1 \mathrm{~h}$. The membranes were washed by PBST three times and incubated with the secondary antibody (goat anti-mouse IgG; cat. no. ab97051; Abcam) at a 1:5,000 dilution in PBST at room temperature for $1 \mathrm{~h}$. Following extensive washing by PBST, the protein bands were visualized by enhanced chemiluminescence kit (ECL; GE Healthcare) substrate. The software used for densitometry was Image J software 1.48 (National Institutes of Health, Bethesda, MD, USA).

Screening of the optimal concentration of GCA-BSA and anti-GCA mAb by indirect ELISA chessboard method. GCA-BSA, including $0.8 \mu \mathrm{g} / \mathrm{ml}$ in Carbonate Buffer (CB) solution, as the initial concentration and coated with $100 \mu \mathrm{l} /$ well on plate, and anti-GCA mAb (1:312.5 in CB as the initial concentration) were diluted in 2-fold series with PBST to the final concentration of $12.5 \mathrm{ng} / \mathrm{ml}$ and 1:320,000, respectively. A non-competitive ELISA assay (Goat Anti-Mouse IgG; cat. no. ab97051; Abcam) was performed. The concentration with the best sensitivity $(0.2 \mu \mathrm{g} / \mathrm{ml}$ for GCA-BSA and 1:10,000 dilution for anti-GCA mAb) was determined as the optimal concentration of GCA-BSA and anti-GCA mAb, and subsequently used in the subsequent icELISA.

Sensitivity identification of the anti-GCA mAb by icELISA. The 96-well microtiter plates were coated by GCA-BSA with $0.2 \mu \mathrm{g} / \mathrm{ml}\left(100 \mu \mathrm{l} /\right.$ well), BSA at $4^{\circ} \mathrm{C}$ overnight. Unoccupied binding sites on the plates were blocked by $1 \%$ BSA in PBS at $37^{\circ} \mathrm{C}$ for $1 \mathrm{~h}$. A total of $50 \mu \mathrm{l} /$ well of GCA $(1 \mu \mathrm{g} / \mathrm{ml}$ diluted in PBS as the initial concentration, 2-fold serial dilutions) acting as competitive reagent, was fully mixed with $50 \mu \mathrm{l} /$ well anti-GCA mAb (dilution, 1:10,000). The mixture was subsequently added onto the plates, while PBS was used as the negative control. The rest of the procedures were same as that of the non-competitive ELISA. Goat anti-mouse IgG conjugated with $\operatorname{HRP}(1: 5,000 ; 100 \mu \mathrm{l} /$ well) was used as the secondary antibody (cat. no. TA130001; OriGene Technologies, Inc.). $\mathrm{OD}$ value was detected at a wavelength of $450 \mathrm{~nm}$. The curves were made with the concentration logarithm of GCA as X-axis, and mean binding rate ratio $\left(\mathrm{B} / \mathrm{B}_{0} \%\right)$ as the $\mathrm{y}$-axis indicating the following: $\mathrm{B}_{0}$ represented the $\mathrm{OD}$ value of the control well without GCA; B represented the OD value of the well with GCA. The $\mathrm{B} / \mathrm{B}_{0}$ generated was plotted versus the logarithmic concentration of GCA to get an inhibition curve (34). A standard line and the linear regression equation was obtained. The $\mathrm{IC}_{50}$ of the anti-GCA mAb against GCA was calculated, and the sensitivity of the mAb was measured by $\mathrm{IC}_{50}(35)$.

For quantitative detection of GCA and its application in HCC cells, icELISA was performed using GCA-BSA as the coated antigen, and using anti-GCA mAb as the detection reagent. The standard line was made with the concentration logarithm of GCA as the x-axis, and the OD450 value as the y-axis. A standard line and the linear regression equation were obtained. According to the standard curve equation, the anti-GCA mAb and icELISA assay can be used to determine GCA concentration within the competitive reagent. Note that in icELISA, the OD450 value was inversely correlated with GCA concentration. 
Application of icELISA in the detection of GCA content in HCC cells. HCCs cell lines, Huh7 and PLC/PRF/5, human hepatocyte cell line, HL-7702, and lung cancer cell line, A549 (China Cell Culture Center, Shanghai, China) were cultured in RPMI-1640 supplemented with 10\% FBS, $100 \mathrm{U} / \mathrm{ml}$ penicillin and $100 \mathrm{U} / \mathrm{ml}$ streptomycin (Gibco; Thermo Fisher Scientific, Inc., Waltham, MA, USA). After $24 \mathrm{~h}$, supernatants were discarded, cells were washed once with PBS and cultured in RPMI-1640 serum (Sigma-Aldrich; Merck KGaA) without FBS for $48 \mathrm{~h}$. The supernatants were collected for icELISA below. All cells $\left(1 \times 10^{5}\right.$ cells/line) were lysed in ice-cold buffer radioimmunoprecipitation assay buffer (RIPA; $50 \mathrm{mM}$ Tris- $\mathrm{HCl}$ pH7.4, $150 \mathrm{mM} \mathrm{NaCl}, 1 \%$ TritonX-100, 0.1\% SDS) and $1 \mathrm{mM}$ phenylmethylsulphonyl fluoride (PMSF) was added at a ratio of PMSF:RIPA 1:100. The two-fold serial dilutions of cell lysates or supernatants were used as competitive reagent in icELISA to detect GCA concentration. Protein in cell lysates and cell supernatants were quantified using a bicinchoninic acid (BCA) assay (Pierce; Thermo Fisher Scientific, Inc.) (32). The same amount of protein $(20 \mu \mathrm{g})$ was two-fold diluted and added as the competitive reagent to detect the GCA concentration in different cell lines lysates or supernatants.

Statistical analysis. Statistical analyses were performed using the SPSS 22.0 software (IBM Corp., Armonk, NY, USA). Values were expressed as mean \pm standard error of the mean. To calculate statistical significant differences among groups, linear regression and the one-way analysis of variance were used. $\mathrm{P}<0.05$ was considered to indicate a statistically significant difference. A Bonferroni post hoc test was used for further statistical analysis between groups.

\section{Results}

Successful conjugation of GCA-BSA immunogen. GCA is a hapten, which, on its own, cannot induce an immune response to produce antibodies in mice. It is necessary to combine GCA with a carrier protein to elicit a specific antibody response (21). Therefore, GCA hydrate $(465.62 \mathrm{~g} / \mathrm{mol})$ was conjugated to the carrier protein BSA $(66.43 \mathrm{kDa})$, with a molecular ratio of 100:1, by the active ester method through amide bonds, using EDC and NHS as the dehydrating agents. GCA-BSA conjugate was purified with a desalting column and identified by SDS-PAGE dyed by $0.25 \%$ Coomassie Brilliant Blue R-250. SDS-PAGE analysis indicated that GCA-BSA conjugate, $100 \mathrm{kDa}$, was successfully generated compared with the control groups, $66.43 \mathrm{kDa}$ (Fig. 1).

The novel anti-GCA $m A b$ indicates high purity and affinity against human GCA. GCA-BSA conjugate was used, in order to immunize the mice. Polyclonal antibodies were generated and obtained. The serum titers were analyzed by indirect non-competitive ELISA. The results indicated that the titer was very high $(>1: 409,000)$, and the GCA-BSA conjugate had successfully induced an immune response. Therefore, the aforementioned results indicated that the GCA-BSA conjugate could be used to prepare hybridomas.

The splenocyte-myeloma hybridomas were obtained by using the standard procedure of hybridoma technique, screened and selected for their capability to examine the anti-GCA mAb by ELISA. Positive clones were subcloned by limiting dilution

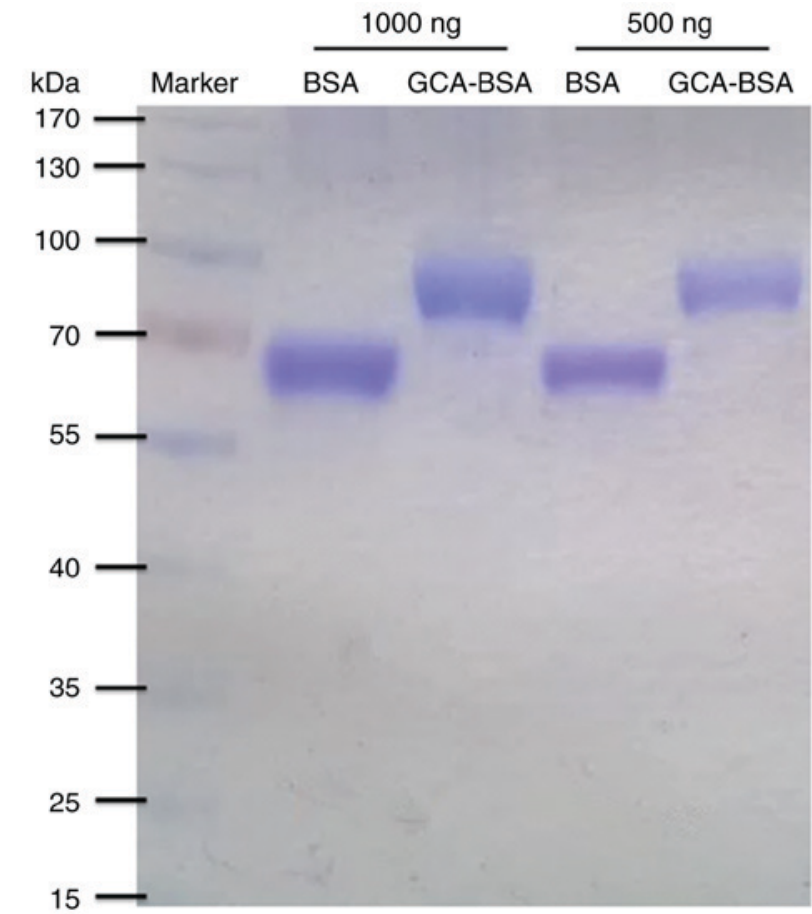

Figure 1. GCA was successfully conjugated to the carrier protein BSA. GCA hydrate $(465.62 \mathrm{~g} / \mathrm{mol})$ was conjugated to the carrier protein BSA $(66.43 \mathrm{kDa})$ with a molecular ratio of 100:1. GCA-BSA was purified and the results indicated that GCA-BSA conjugate, $100 \mathrm{kDa}$, was successfully generated. GCA, glycocholic acid; BSA, bovine serum albumin; GCA-BSA, GCA-BSA conjugate.

method to obtain mAbs. The positive hybridoma cells were subsequently peritoneally injected into the female BALB/c mice, and the ascites were generated and purified by ammonium sulfate precipitation, followed further depuration by protein- $G$ affinity chromatography, according to the manufacturer's protocols (30). Furthermore, the purity of mAb was identified by SDS-PAGE (dyed by Coomassie Brilliant Blue R-250). Antibodies have two chains, where the heavy chain molecular weight is $50-75 \mathrm{kDa}$, and the light chain molecular weight is $\sim 25 \mathrm{kDa}$ (29). The SDS-PAGE data demonstrated that the purified anti-GCA mAb (Lane 2) had only two chains compared with the unpurified antibodies (Lane 1), and the heavy chain of anti-GCA mAb was $\sim 55 \mathrm{kDa}$ and the light chain was $\sim 25 \mathrm{kDa}$ (Fig. 2A), indicating that the $\mathrm{mAb}$ was successfully obtained and purified.

The affinity of anti-GCA $m A b$. Furthermore, the affinity of anti-GCA mAb was tested by non-competitive ELISA as described previously (31). The OD values at a wavelength of $450 \mathrm{~nm}$ were detected. The curve diagram was made and the affinity of the antibody was obtained (31). The affinity constant of antigen-antibody interaction was designed by the equation average affinity constant $(\mathrm{Kaff})=(\mathrm{n}-1) / 2\left[\mathrm{n}\left(\mathrm{Ab} \mathrm{b}^{\prime}\right) \mathrm{t}-(\mathrm{Ab}) \mathrm{t}\right]$. It was reported that an antibody with an affinity constant between $10^{7}-10^{12} \mathrm{~mol} / \mathrm{l}$ has a good potential for application (36). The Kaff of anti-GCA mAb was $2.6 \times 10^{8} \mathrm{~mol} / \mathrm{l}$ determined by non-competitive ELISA (Fig. 2B). Therefore, high affinity anti-GCA mAb was successfully generated and purified. The isotype of mAb was further analyzed with an Antibody Isotyping kit, according to manufacturer's protocols (32) and the isotype of heavy chain and light chain of the mouse anti-GCA mAb were IgG2a and $\kappa$, respectively. 

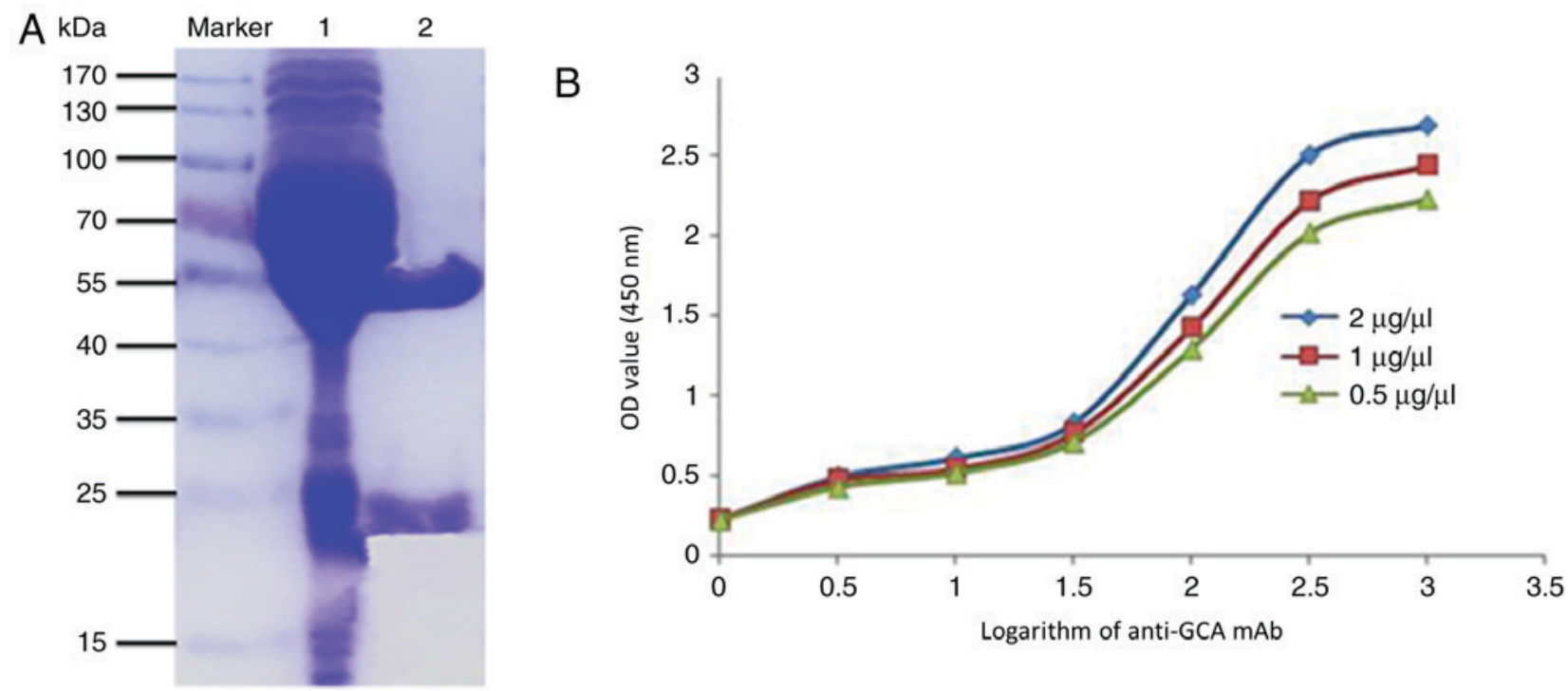

Figure 2. The novel anti-GCA mAb indicates high purity and affinity against human GCA. (A) Purity of mAb identified by SDS-PAGE (dyed by Coomassie Brilliant Blue R-250). Marker, standard protein marker; Lane 1, unpurified ascites fluid; Lane 2, purified anti-GCA mAb. (B) The affinity curves of the anti-GCA mAb. The affinity constant of antigen-antibody interaction was designed by the equation Kaff. GCA, glycocholic acid; OD, optical density; mAb, monoclonal antibody; Kaff, average affinity constant.

The anti-GCA mAb is highly specific against human GCA. The specificity of anti-GCA mAb to human GCA was analyzed by competitive western blot analysis. BSA and GCA-BSA were separated by $10 \%$ SDS-PAGE, which was detected by Coomassie Brilliant Blue R-250, according to the manufacturer's protocols. The molecular weight of BSA was $66.43 \mathrm{kDa}$ (range, 55-70 kDa), while the molecular weight of GCA-BSA $(\sim 100 \mathrm{kDa})$ was significantly increased $(\mathrm{P}<0.001)$, compared with that of BSA. SDS-PAGE results indicated that the molecular weights of BSA and GCA-BSA were correct and were able to be used as a control (Fig. 3A). To analyze the specificity of the anti-GCA mAb, BSA and GCA-BSA were separated by $10 \%$ SDS-PAGE, and subsequently electro-transferred to a PVDF membrane. The band of the competitive group was significantly weaker $(\mathrm{P}<0.001)$, compared with that of the non-competitive group (Fig. 3B), indicating that the anti-GCA mAb was highly specific against human GCA.

Anti-GCA mAb is highly sensitive toward human GCA. The sensitivity of anti-GCA mAb to human GCA was analyzed by icELISA. Anti-GCA mAb was used as the primary antibody and a series of diluted GCA $(1,2,4,8,16,32,64 \mathrm{x}$, and $0 \mathrm{x}$ as the control) were used as the competitive reagent. The curves were made with the concentration logarithm of GCA as the $\mathrm{x}$-axis, and the mean binding rate ratio $\left(\mathrm{B} / \mathrm{B}_{0}\right)$ as the $\mathrm{y}$-axis. $\mathrm{B}_{0}$ was the OD value of the control well without GCA, and $\mathrm{B}$ was the OD value of the well with GCA. According to the curves, the following linear regression equation was obtained: $y=-38.837 x+129.25$, and the correlation coefficient $\left(r^{2}\right)$ was 0.9955. According to the regression equation, $\mathrm{IC}_{50}$ of $\mathrm{mAb}$ binding to GCA-BSA was calculated to be $0.1098 \mu \mathrm{g} / \mathrm{ml}$, indicating the sensitivity of anti-GCA mAb was notably high (Fig. 4A). It was observed that the lower the $\mathrm{IC}_{50}$ was, the higher the sensitivity of anti-GCA mAb.

For quantitative detection of GCA and its application in HCC cells, icELISA was performed using GCA-BSA as the coated antigen, and anti-GCA mAb as the detection reagent. The standard line was made with the concentration logarithm of GCA as the $\mathrm{x}$-axis, and $\mathrm{OD}_{450} \mathrm{~nm}$ value as the $\mathrm{y}$-axis. The standard line indicates a good sensibility and reliability of the icELISA method, which is capable of detecting GCA between $0.01563-1 \mu \mathrm{g} / \mathrm{ml}$. The linear regression equation was $y=-0.6723 x+2.2372$ and the correlation coefficient was 0.9956 (Fig. 4B). The result indicated that $\mathrm{OD}_{450} \mathrm{~nm}$ absorbance was inversely correlated with GCA competitive reagent, indicating that the anti-GCA mAb and icELISA assay can be used to determine GCA concentration within the competitive reagent. It was also indicated in icELISA that the $\mathrm{OD}_{450}$ value was inversely correlated with GCA concentration.

GCA is significantly elevated in HCC cells, compared with normal human hepatocytes or lung cancer cells. In order to determine if anti-GCA mAb can be used to detect GCA in HCC cells, cell lysates and supernatants from HCC cell line Huh7 and PLC/PRF/5, human hepatocyte cell line, HL-7702, and lung cancer cell line, A549, were analyzed by icELISA. The two-fold serial dilutions of the cell lysates or supernatants, starting with the same number of cells for each cell line, were used as the competitive reagent. The GCA in each sample was subsequently calculated, according to the previous linear regression equation $y=-0.6723 x+2.2372$. Consistent with previous results (11), it was indicated that the GCA level in Huh7 and PLC/PRF/5 cells was significantly increased, compared with HL-7702 and A549 cells (Fig. 5A-D). GCA level in A549 cells was similar to blank control value (Fig. 5A and C).

The protein concentration was subsequently quantified with a BCA assay. Same amount of proteins $(20 \mu \mathrm{g})$ were used to make series of two-fold dilutions. GCA level from above cell lysates and supernatants of HCC cell Huh7 and PLC/PRF/5, human hepatocyte HL-7702, lung cancer cell A549 were analyzed again by icELISA. Significantly increased levels of GCA were detected in HCC cell lines Huh7 and PLC/PRF/5, 


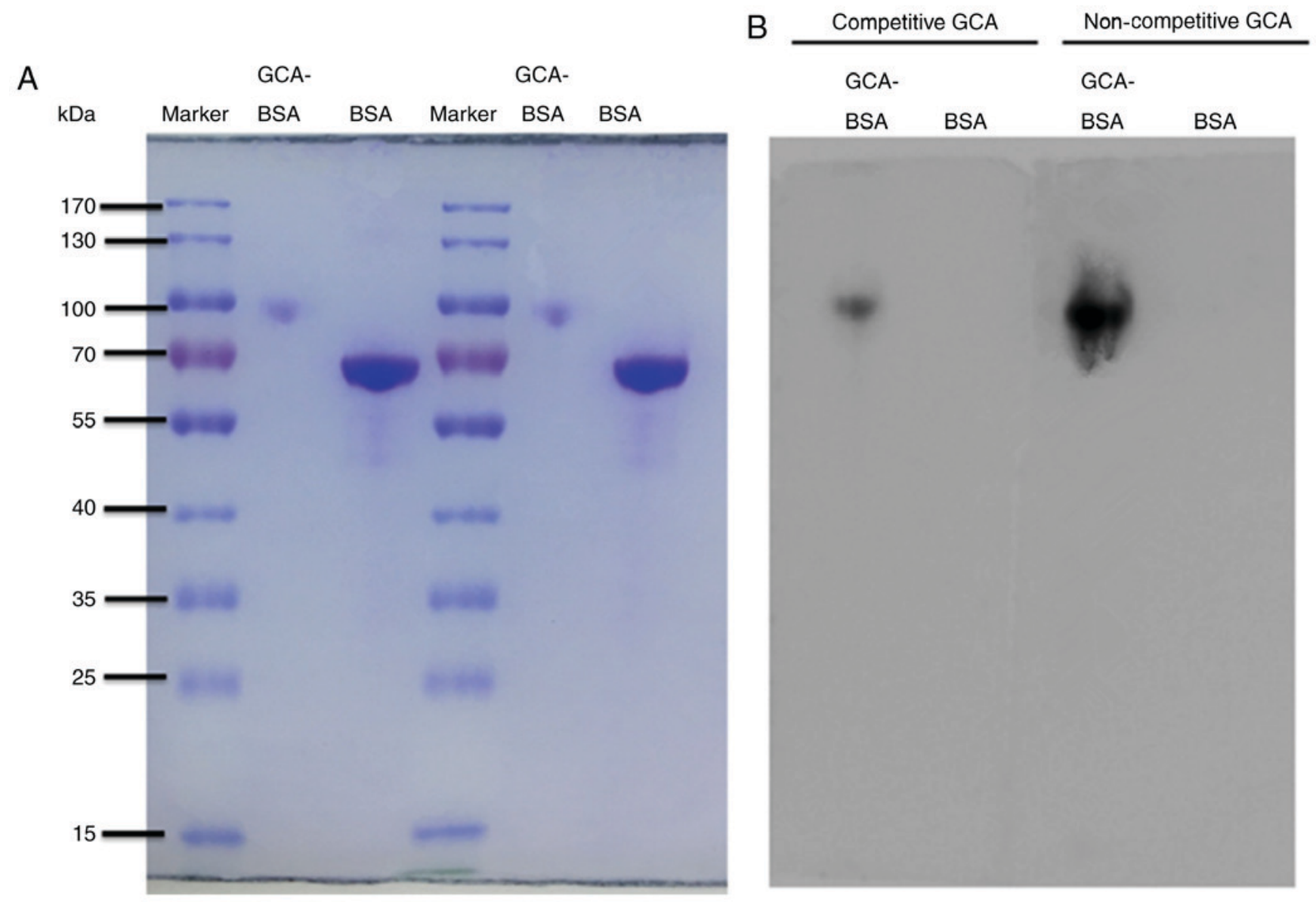

Figure 3. The anti-GCA mAb was highly specific against human GCA. (A) The molecular weight of GCA-BSA ( 100 kDa) was significantly increased, compared with the molecular weight of BSA, $66.43 \mathrm{kDa}$ (range, 55-70 kDa). SDS-PAGE results were used as the control. (B) BSA and GCA-BSA were separated by SDS-PAGE and electro-transferred to a PVDF membrane. The PVDF membrane was cut into two identical parts. Competitive group, 5 ml GCA $(10 \mu \mathrm{g} / \mathrm{ml})$ added to $5 \mathrm{ml}$ anti-GCA mAb $(1: 1,000)$; non-competitive group, $5 \mathrm{ml}$ PBST added to $5 \mathrm{ml}$ anti-GCA mAb $(1: 1,000)$. The secondary antibody of all lanes was goat anti-mouse $\operatorname{IgG}(1: 5,000)$. The band of the competitive group was significantly weaker, compared with the non-competitive group. GCA, glycocholic acid; mAb, monoclonal antibody; BSA, bovine serum albumin; GCA-BSA, GCA-BSA conjugate; PVDF, polyvinylidene fluoride membrane; PBST, Tween-20 PBS.
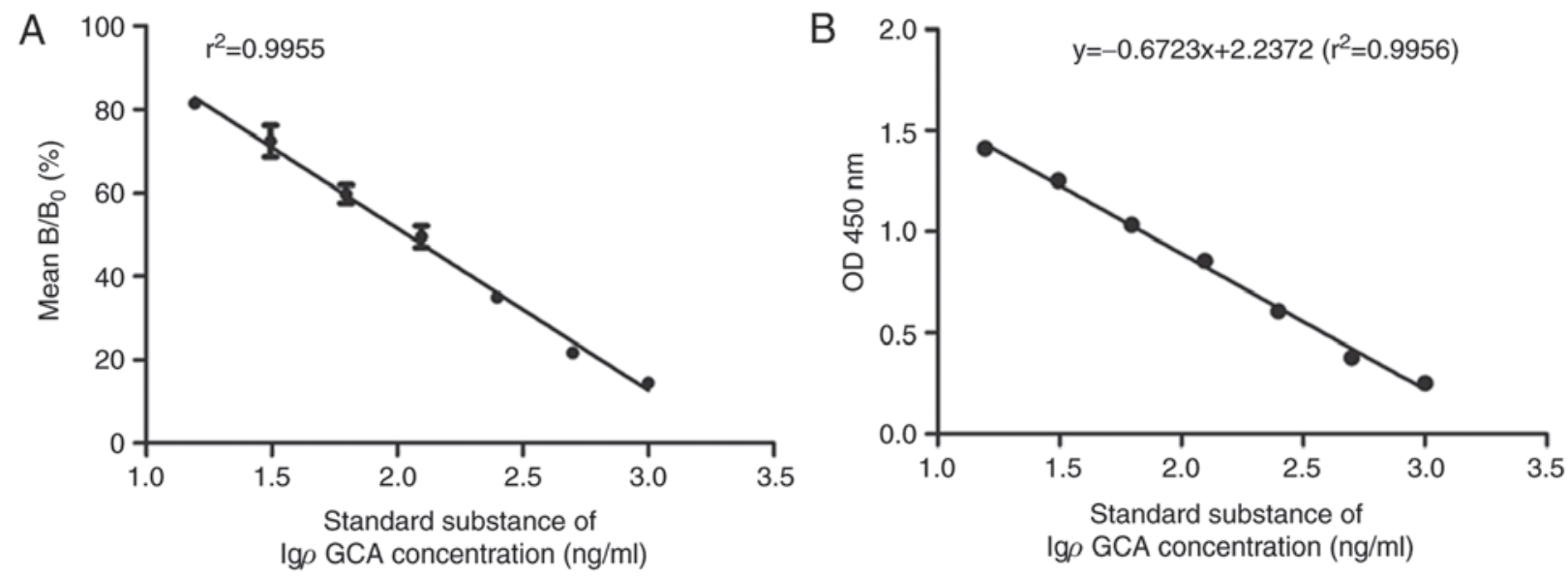

Figure 4. The anti-GCA mAb was identified with high sensitivity through icELISA. The anti-GCA mAb was used as the primary antibody, and a series of diluted GCA were used as the competitive reagent. The OD value was measured at a wavelength of $450 \mathrm{~nm}$. (A) The binding rate as ordinate of GCA. The curves were generated with the concentration logarithm of GCA as the x-axis and the mean binding rate ratio (B/B0\%) as the y-axis. B0 represents the OD value of the control well without GCA and B represents the OD value of the well with GCA. The B/B0 was plotted versus the logarithmic concentration of GCA to provide an inhibition curve. The concentration of competitive reagent GCA, when $\mathrm{B} / \mathrm{B}_{0}=50 \%$, was determined as $\mathrm{IC}_{50}$. IC $\mathrm{I}_{50}$ was calculated according to the standard curve derived regression equation to measure the sensitivity. (B) The coefficient correlation analysis of the OD value at a wavelength of $450 \mathrm{~nm}$ and the concentration logarithm of GCA. The $y$-axis represents the $\mathrm{OD}_{450} \mathrm{~nm}$ value. The y-axis indicates the two-fold serial dilution of the logarithm GCA concentration starting from $1 \mu \mathrm{g} / \mathrm{ml}$. Standard line indicates a good sensibility and reliability of the capability of the icELISA method to detect GCA between $0.01563-1 \mu \mathrm{g} / \mathrm{ml}$. The GCA concentration was inversely correlated with $\mathrm{OD}_{450}$. GCA, glycocholic acid; Ig@ GCA, the logarithm of the GCA concentration based on 10; OD, optical density; $\mathrm{IC}_{50}, 50 \%$ inhibitory rate; icELISA, indirect competitive ELISA. 
A

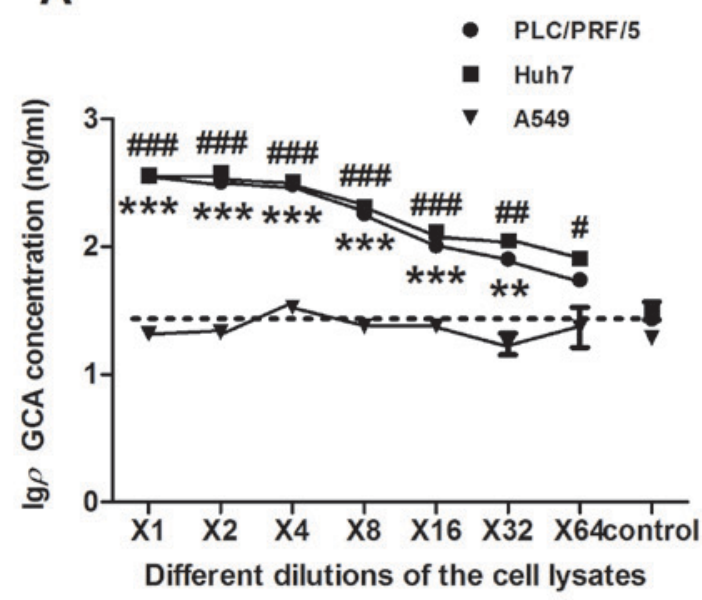

C

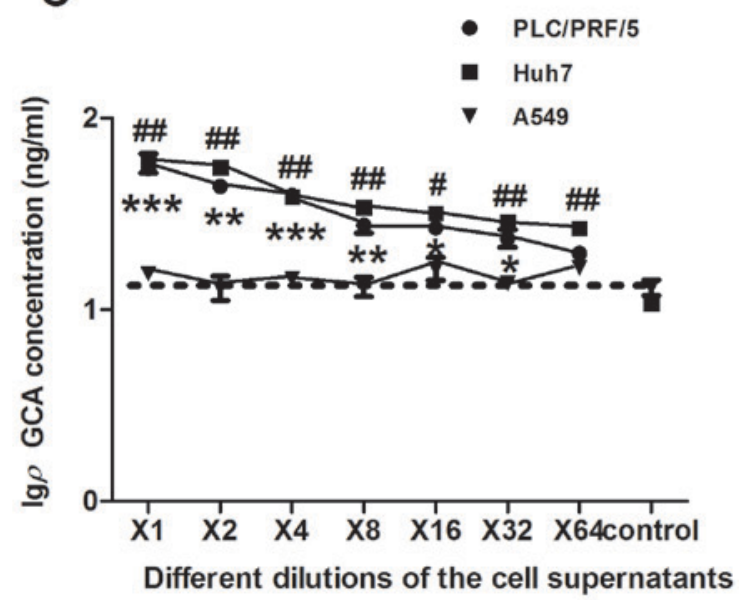

B

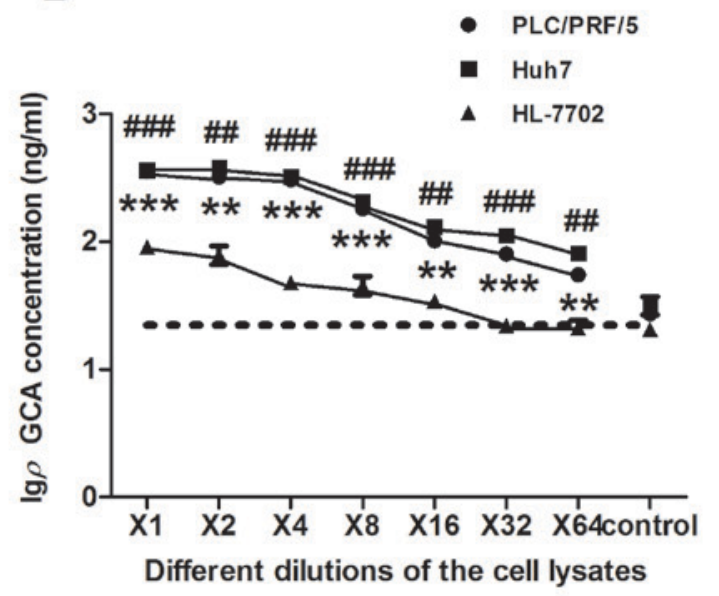

D

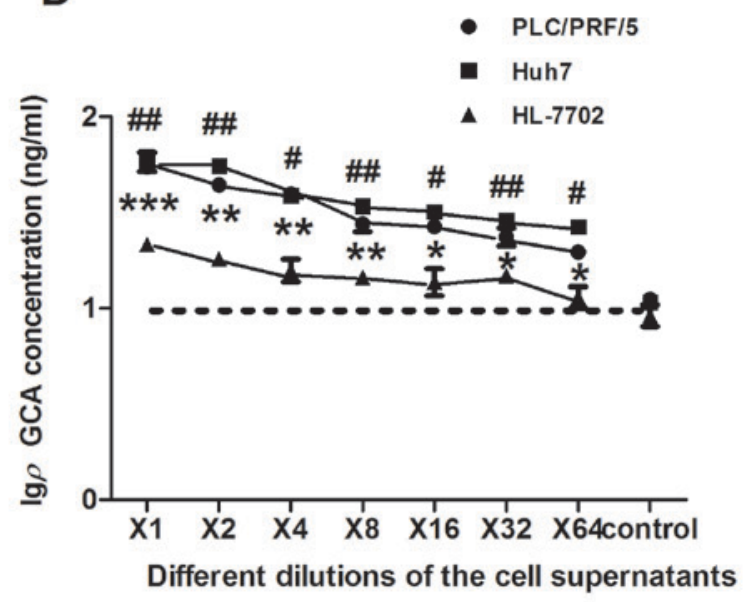

Figure 5. The significantly elevated amount of GCA was detected in HCC cells, compared with normal human hepatocytes and lung cancer cells. Cell lysates and supernatants from HCC cell lines Huh7 and PLC/PRF/5, human hepatocyte cell line HL-7702 and lung cancer cell line A549 were collected and analyzed by icELISA. The two-fold serial dilutions of the cell lysates or supernatants were used as the competitive reagent. The GCA content in each sample was then calculated according to the linear regression equation $y=-0.6723 x+2.2372$. (A) icELISA analysis of GCA content was examined in cell lysate using the same number of different cells in Huh7 and PLC/PRF/5 cells, compared with A549 cells. ${ }^{* *} \mathrm{P}<0.01,{ }^{* * *} \mathrm{P}<0.001,{ }^{\# \mathrm{P}}<0.05$, ${ }^{\# \#} \mathrm{P}<0.01$ and ${ }^{\# \# \#} \mathrm{P}<0.001$ vs. A549 cells. (B) icELISA analysis of GCA content was examined in cell lysate using the same number of different cells in Huh7 and PLC/PRF/5 cell lines, compared with HL-7702 cells. ${ }^{* *} \mathrm{P}<0.01,{ }^{* * *} \mathrm{P}<0.001,{ }^{\# \#} \mathrm{P}<0.01$ and ${ }^{\# \# \#} \mathrm{P}<0.001$ vs. HL-7702 cells. (C) icELISA analysis of GCA content was examined in the supernatant using the same number of different cells in Huh7 and PLC/PRF/5 cells, compared with A549 cells. ${ }^{*} \mathrm{P}<0.05,{ }^{* *} \mathrm{P}<0.01,{ }^{* * *} \mathrm{P}<0.001$ and ${ }^{\#} \mathrm{P}<0.05$ vs. A549 cells. (D) icELISA analysis of GCA content was examined in the supernatant using the same number of different cells in Huh7 and PLC/PRF/5 cell lines, compared with HL-7702 cells. ${ }^{*} \mathrm{P}<0.05,{ }^{* *} \mathrm{P}<0.01,{ }^{* * *} \mathrm{P}<0.001,{ }^{*} \mathrm{P}<0.05$ and ${ }^{\# \#} \mathrm{P}<0.01$ vs. HL-7702 cells. The dashed line in each figure represent the blank control value (RPMI-1640 without FBS). The x-axis is the two-fold serial dilutions of the cell line lysates or supernatants The y-axis represents the Ig@ GCA concentration. GCA, glycocholic acid; icELISA, indirect competitive ELISA; HCC, hepatocellular carcinoma; Ige GCA, the logarithm of the GCA concentration based on 10.

compared with A549 or HL-7702 cells (Fig. 6A-D), which was consistent with the results indicated in Fig. 5A-D. In conclusion, the results of the present study indicated that icELISA analysis based on the novel anti-GCA mAb can be successfully used for a rapid, sensitive and efficient detection of GCA from different HCC cell lines. Therefore, icELISA analysis may have great potential for further clinical application.

\section{Discussion}

GCA is a combination of cholic acid and glycine, with a molecular weight of $466.3 \mathrm{Da}$ and one of the main components of bile acids (12). The main function of GCA is to participate in the digestion of fat, as it also occurs as a sodium salt in the bile of mammals. In normal conditions, GCA content in peripheral blood is very low and stable, regardless of fasting or after-meal, with a blood concentration $<3 \mu \mathrm{g} / \mathrm{ml}$ in healthy individuals (37). However, under the conditions of hepatocytes injury or cholestasis, abnormal metabolism and circulation of bile acids would decrease the absorbance of cholic acid, resulting in an increased GCA level in the blood, positively correlated with the severity of hepatocyte damage and the metabolic dysfunction of bile acid $(38,39)$.

A number of studies have indicated that GCA, as a clinical marker to detect liver diseases including HCC, chronic active hepatitis, chronic active hepatitis and chronic active hepatitis (40), has numerous advantages compared with the traditional liver function tests, including alanine aminotransferase, aspartate transaminase and gamma-glutamyltranspeptidase $(41,42)$. Therefore, GCA analysis can provide 
A

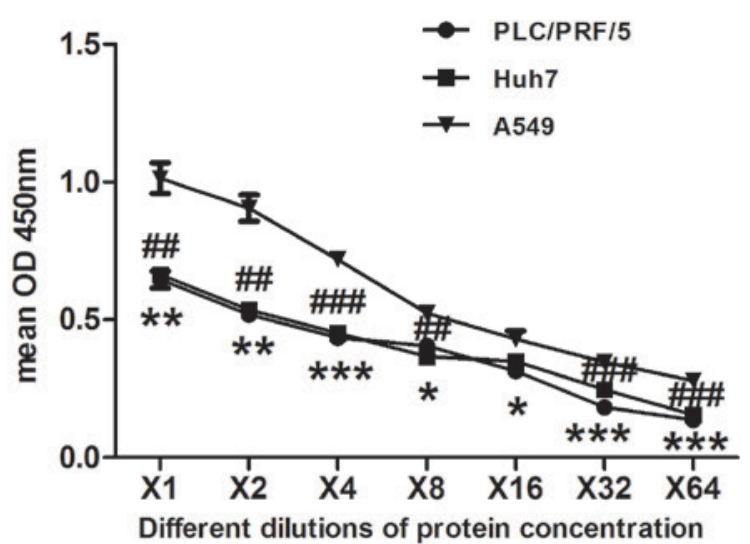

C

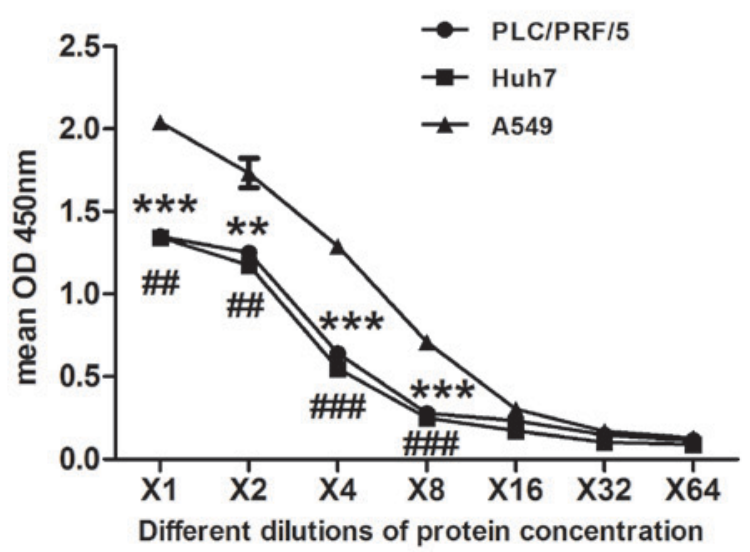

B

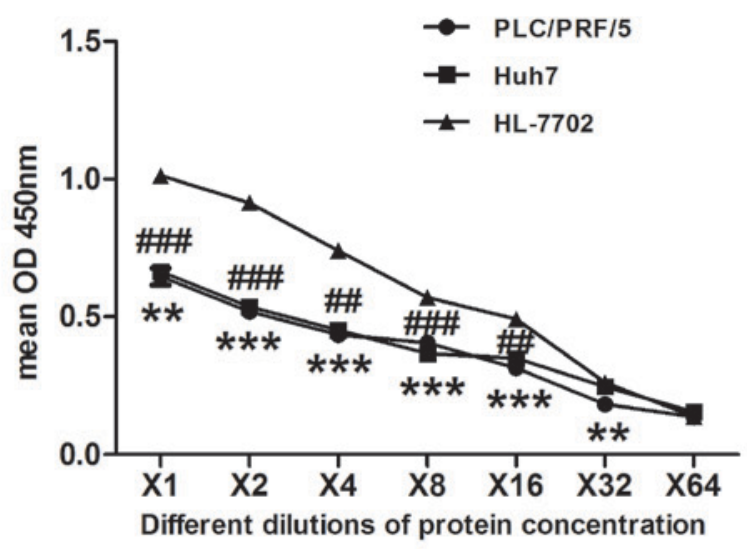

D

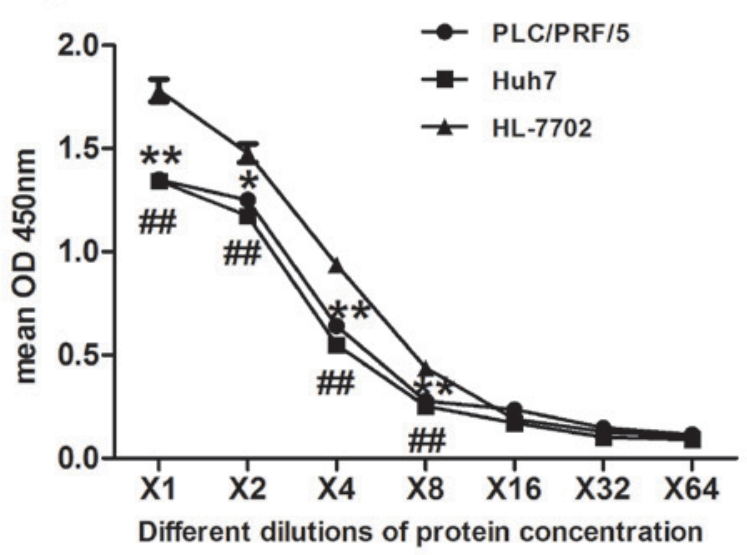

Figure 6. The significantly elevated amount of GCA was detected in HCC cells, compared with normal human hepatocytes and lung cancer cells. Cell lysates and supernatants from HCC cell lines Huh7 and PLC/PRF/5, human hepatocyte cell line HL-7702 and lung cancer cell line A549 were collected and analyzed by icELISA. The 2-fold serial dilutions of the cell lysates or supernatants were used as the competitive reagent. The GCA content in each sample was then calculated according to the linear regression equation $y=-0.6723 x+2.2372$. Quantified protein concentration using a bicinchoninic acid assay where $y$-axis indicates $\mathrm{OD}_{450}$, which is inversely correlated to GCA concentration. Same amount of protein (20 $\left.\mu \mathrm{g}\right)$ was used to make series of two-fold dilutions. (A) Mean $\mathrm{OD}_{450}$ of GCA contents was examined in cell lysate using the same protein amount of different cells in Huh7 and PLC/PRF/5 cells, compared with A549. ${ }^{*} \mathrm{P}<0.05,{ }^{* *} \mathrm{P}<0.01,{ }^{* * *} \mathrm{P}<0.001,{ }^{\# \#} \mathrm{P}<0.01$ and ${ }^{\# \# \#} \mathrm{P}<0.001$ vs. A549 cells. (B) Mean $\mathrm{OD}_{450}$ of GCA contents was examined in cell lysate using the same protein amount of different cells in Huh7 and PLC/PRF/5 cell lines, compared with HL-7702 cells. ${ }^{* *} \mathrm{P}<0.01,{ }^{* * * *} \mathrm{P}<0.001,{ }^{\# \#} \mathrm{P}<0.01$ and ${ }^{\# \# \#} \mathrm{P}<0.001$ vs. HL-7702 cells. (C) Mean $\mathrm{OD}_{450}$ of GCA contents was examined in the supernatant using the same protein amount of different cells in Huh7 and PLC/PRF/5 cells, compared with A549 cells. ${ }^{* *} \mathrm{P}<0.01$ and ${ }^{* * * *} \mathrm{P}<0.001{ }^{\# \#} \mathrm{P}<0.01$ and ${ }^{\# \# \#} \mathrm{P}<0.001$ vs. A549 cells. (D) Mean OD 450 of GCA contents was examined in the supernatant using the same protein amount of different cells in Huh7 and PLC/PRF/5 cell lines, compared with HL-7702 cells. ${ }^{*} \mathrm{P}<0.05,^{* *} \mathrm{P}<0.01$ and ${ }^{\# \# ~} \mathrm{P}<0.01$ vs. HL-7702 cells. GCA, glycocholic acid; OD, optical density; icELISA, indirect competitive ELISA; HCC, hepatocellular carcinoma.

the basic information for diagnosis, treatment and prognosis of liver diseases, various biliary system diseases, including cholangiocarcinoma (43), intrahepatic cholestasis and alcoholic liver injury $(39,44)$. HCC has a high morbidity and mortality rate. Early-stage diagnosis of HCC can greatly reduce the mortality and increase disease-free rate. Therefore, further studies are required to identify a sensitive marker for the diagnosis of HCC. A number of previous studies have identified that GCA is a sensitive biomarker for HCC diagnosis $(12,37,41)$.

The aim of the present study was to establish an effective icELISA method, based on the anti-GCA mAb for detection of GCA, in order to provide a simple, rapid, convenient, and reliable way to detect GCA, therefore, promoting early diagnosis of HCC. Synthesized human GCA hydrate $\left(\mathrm{C}_{26} \mathrm{H}_{43} \mathrm{NO}_{6} \cdot \mathrm{XH}_{2} \mathrm{O}\right.$, $465.62 \mathrm{~g} / \mathrm{mol})$, as a hapten, was first conjugated with BSA $(66.43$ $\mathrm{kDa}$ ) to form a complete antigen by the active ester method, as verified by SDS-PAGE. GCA-BSA conjugate was used to immunize mice, and the anti-serum specific to GCA with high titer (>1:409,000) was acquired. Using GCA-BSA conjugate as the immunogen, a hybridoma capable of generating anti-GCA $\mathrm{mAb}$, was successfully obtained by hybridoma technique (45). Ascites were generated to obtain abundant $\mathrm{mAb}$ for further purification and detection by SDS-PAGE. The isotype of the anti-GCA mAb was examined to be $\operatorname{IgG} 2 \mathrm{a}$ and $\kappa$. The affinity constant of anti-GCA mAb was $2.6 \times 10^{8} \mathrm{~mol} / 1$. Furthermore, the high specificity of anti-GCA mAb was determined by competitive western blot analysis using GCA as the competitive reagent. The results indicated that the binding between anti-GCA mAb and GCA-BSA can be almost fully inhibited by free GCA.

Additionally, icELISA was established to detect the expression of GCA in supernatant and lysate in a number of cell lines. Previous studies indicated the expression of GCA increased significantly in liver cancer $(12,37,43)$. In the present study, the expression of GCA in human normal hepatocyte cell line (HL-7702), human HCC cell lines (PLC/PRF/5 and Huh7) 
and lung adenocarcinoma cell line (A549) was detected. The results from cell lysate of the different cells were similar to that from cell supernatant, indicating that GCA expression was significantly elevated in PLC/PRF/5 and Huh7, compared with HL-7702 and A549. In order to further verify this result, under the same protein amount, using a BCA protein assay kit, GCA expression was indicated to be significantly elevated in PLC/PRF/5 and Huh7 cells, compared with HL-7702 and A549 cells. Therefore, the results of the present study strongly indicate that the icELISA method using the novel anti-GCA $\mathrm{mAb}$ could be of great clinical assistance, in addition to being sensitive to detecting GCA in HCC.

The present study data also indicates that GCA may be used as a sensitive biomarker in HCC, which is consistent with the results from other groups $(13,46)$. A number of studies have reported that there is a linear association between GCA and the severity of hepatocyte dysfunction $(37,43)$. With the progress of hepatobiliary diseases, GCA has been reported to demonstrate a trend of gradual increase (47). A number of researchers have proposed the use of chenodeoxycholic acid ratio and the vein $14 \mathrm{C}$ cholylglycine tolerance test, as a method for differential diagnosis of liver diseases $(48,49)$. It has been also reported that GCA in human plasma and urine from patients with HCC was significantly increased, compared with healthy individuals (13). These results indicate the broad application of GCA in the detection of hepatobiliary diseases and $\mathrm{HCC}$, as GCA is a more sensitive marker. The novel anti-GCA $\mathrm{mAb}$ and icELISA assay may qualify for a simple, more rapid and efficient detection method for GCA.

In conclusion, a novel anti-GCA mAb was successfully generated in the present study, exhibiting a low $\mathrm{IC}_{50}$, high specificity and sensitivity for GCA binding. An icELISA was further established to detect the level of GCA in cells or body fluids, reflecting the dynamic process of hepatocellular injury. Therefore, these observations indicate the promising extensive clinical application of GCA for early HCC diagnosis, and provide novel insight for further research and treatment of HCC and other hepatobiliary diseases.

\section{Acknowledgements}

Not applicable.

\section{Funding}

The present study was supported by the Youth Fund of National Natural Science Foundation of China (grant No. 81600456) to NL.

\section{Availability of data and materials}

All data generated or analyzed during the present study are included in this published article.

\section{Authors' contributions}

MW made substantial contributions to conception, design, and acquisition of data and was a major contributor in writing the manuscript. SHZ and JG analyzed the data, design and were involved in drafting the manuscript. DPW made contributions to resource, data acquisition and analysis. JXX made contributions to methodology. YXZ made contributions to investigation and supervision. NL was involved in revising the manuscript critically for important intellectual content and agreed to be accountable for all aspects of the work in ensuring that questions related to the accuracy of the work are appropriately investigated and resolved. NL also made contributions to conception, methodology and interpretation of data. LJH made substantial contributions to conception, design, revised the manuscript and was the project supervisor. All authors read and approved the final manuscript.

\section{Ethics approval and consent to participate}

Ethical approval for the use of animals was obtained from the Research Ethics Committee of West China School of Basic Medical Sciences and Forensic Medicine, Sichuan University (Sichuan, China). All experimental procedures complied with the Sichuan University Committee Guidelines on the Use of Live Animals in Research, in accordance with the National Institutes of Health Guide for the Care and Use of Laboratory Animals (NIH Publications No. 80-23), revised in 1978.

\section{Patient consent for publication}

Not applicable.

\section{Competing interests}

The authors declare that they have no conflict of interest.

\section{References}

1. Raghunath A, Sundarraj K, Arfuso F, Sethi G and Perumal E: Dysregulation of nrf2 in hepatocellular carcinoma: Role in cancer progression and chemoresistance. Cancers (Basel) 10: E481, 2018.

2. Zhang Z, Zhang Y, Wang Y,Xu Land Xu W: Alpha-fetoprotein-L3 and Golgi protein 73 may serve as candidate biomarkers for diagnosing alpha-fetoprotein-negative hepatocellular carcinoma. Onco Targets Ther 9: 123-129, 2015.

3. Schuette D, Moore LM, Robert ME, Taddei TH and Ehrlich BE: Hepatocellular carcinoma outcome is predicted by expression of neuronal calcium sensor 1. Cancer Epidemiol Biomarkers Prev 27: 1091-1100, 2018.

4. Llovet JM, Burroughs A and Bruix J: Hepatocellular carcinoma. Lancet 362: 1907-1917, 2003.

5. Altekruse SF, McGlynn KA and Reichman ME: Hepatocellular carcinoma incidence, mortality, and survival trends in the United States from 1975 to 2005. J Clin Oncol 27: 1485-1491, 2009.

6. Siegel R, Naishadham D and Jemal A: Cancer statistics, 2013. CA Cancer J Clin 63: 11-30, 2013.

7. Hernandez-Gea V, Turon F, Berzigotti A and Villanueva A: Management of small hepatocellular carcinoma in cirrhosis: Focus on portal hypertension. World J Gastroenterol 19: 1193-1199, 2013.

8. Wang W and You J: Research and application of (18) F-fluorodeoxyglucose positron emission tomography/computed tomography for the diagnosis and treatment of primary hepatocellular carcinoma. Sheng Wu Yi Xue Gong Cheng Xue Za Zhi 34: 480-484, 2017 (In Chinese; Abstract available in Chinese from the publisher).

9. Guo W, Tan HY, Wang N, Wang X and Feng Y: Deciphering hepatocellular carcinoma through metabolomics: From biomarker discovery to therapy evaluation. Cancer Manag Res 10: 715-734, 2018. 
10. Ressom HW, Xiao JF, Tuli L, Varghese RS, Zhou B, Tsai TH, Ranjbar MR, Zhao Y, Wang J, Di Poto C, et al: Utilization of metabolomics to identify serum biomarkers for hepatocellular carcinoma in patients with liver cirrhosis. Anal Chim Acta 743: 90-100, 2012.

11. Li H, Fan SF, Wang Y, Shen SG and Sun DX: Rapid detection of small molecule metabolites in serum of hepatocellular carcinoma patients using ultrafast liquid chromatography-ion trap-time of flight tandem mass spectrometry. Anal Sci 33: 573-578, 2017.

12. Zhang A, Sun H, Yan G, Han Y, Ye Y and Wang X: Urinary metabolic profiling identifies a key role for glycocholic acid in human liver cancer by ultra-performance liquid-chromatography coupled with high-definition mass spectrometry. Clin Chim Acta 418: 86-90, 2013

13. Li QF, Zhan YM, Zhong YG, Zhang $B$ and Ge CQ: Macromolecular crowding agents-assisted imprinted polymers for analysis of glycocholic acid in human plasma and urine. Biomed Chromatogr 30: 1706-1713, 2016.

14. Martinot E, Sedes L, Baptissart M, Lobaccaro JM, Caira F, Beaudoin C and Volle DH: Bile acids and their receptors. Mol Aspects Med 56: 2-9, 2017.

15. Cui X, Vasylieva N, Shen D, Barnych B, Yang J, He Q, Jiang Z, Zhao S and Hammock BD: Biotinylated single-chain variable fragment-based enzyme-linked immunosorbent assay for glycocholic acid. Analyst 143: 2057-2065, 2018.

16. Guo C, Xie C, Ding P, Qin G, Mo W, Cao X and Zheng S: Quantification of glycocholic acid in human serum by stable isotope dilution ultra performance liquid chromatography electrospray ionization tandem mass spectrometry. J Chromatogr B Analyt Technol Biomed Life Sci 1072: 315-319, 2018.

17. Luo L, Schomaker S, Houle C, Aubrecht J and Colangelo JL: Evaluation of serum bile acid profiles as biomarkers of liver injury in rodents. Toxicol Sci 137: 12-25, 2014.

18. Trottier J, Bialek A, Caron P, Straka RJ, Milkiewicz P and Barbier O: Profiling circulating and urinary bile acids in patients with biliary obstruction before and after biliary stenting. PLoS One 6: e22094, 2011.

19. Xiao JF, Varghese RS, Zhou B, Nezami Ranjbar MR, Zhao Y, Tsai TH, Di Poto C, Wang J, Goerlitz D, Luo Y, et al: LC-MS based serum metabolomics for identification of hepatocellular carcinoma biomarkers in egyptian cohort. J Proteome Res 11: 5914-5923, 2012.

20. Schmid A, Neumann H, Karrasch T, Liebisch G and Schaffler A: Bile acid metabolome after an oral lipid tolerance test by liquid chromatography-tandem mass spectrometry (Lc-Ms/Ms). PLoS One 11: e0148869, 2016.

21. Cui X, Vasylieva N, Wu P, Barnych B, Yang J, Shen D, He Q, Gee SJ, Zhao S and Hammock BD: Development of an indirect competitive enzyme-linked immunosorbent assay for glycocholic acid based on chicken single-chain variable fragment antibodies. Anal Chem 89: 11091-11097, 2017

22. Hua J, Li Z, Xia W, Yang N, Gong J, Zhang J and Qiao C: Preparation and properties of EDC/NHS mediated crosslinking poly (gamma-glutamic acid)/epsilon-polylysine hydrogels. Mater Sci Eng C Mater Biol Appl 61: 879-892, 2016.

23. Schrama D, Reisfeld RA and Becker JC: Antibody targeted drugs as cancer therapeutics. Nat Rev Drug Discov 5: 147-159, 2006.

24. Kumar G: Fungal laccase efficiently destains coomassie brilliant blue-R-250 stained polyacrylamide gels. Methods Mol Biol 1853: 247-253, 2018

25. National Research Council (US) Committee for the Update of the Guide for the Care and Use of Laboratory Animals: Guide for the Care and Use of Laboratory Animals. The National Academies Collection: Reports funded by National Institutes of Health. 8th edition. Washington (DC), USA 2011.

26. Seong GS, Sohn HJ, Kang H, Seo GE, Kim JH and Shin HJ: Production and characterization of monoclonal antibodies against cathepsin B and cathepsin B-Like proteins of naegleria fowleri. Exp Parasitol 183: 171-177, 2017.

27. Kohler G and Milstein C: Continuous cultures of fused cells secreting antibody of predefined specificity. Nature 256: 495-497, 1975.

28. Kim JH, Lee J, Sohn HJ, Song HO, Kim JY, Lee WJ, Park H and Shin HJ: Production of monoclonal antibodies for Plasmodium vivax lactate dehydrogenase and patient sera screening using sandwich ELISA. Parasitol Res 111: 1645-1650, 2012.

29. Chen Q, Qiu S, Li H, Lin C, Luo Y, Ren W, Zou Y, Wang Y, Xia N and Huang C: A novel approach for rapid high-throughput selection of recombinant functional rat monoclonal antibodies. BMC Immunol 19: 35, 2018
30. Zarei S, Bayat AA, Hadavi R, Mahmoudi AR, Tavangar B, Vojgani Y, Jeddi-Tehrani M and Amirghofran Z: Production and characterization of a peptide-based monoclonal antibody against CD44 variant 6. Monoclon Antib Immunodiagn Immunother 34: 36-43, 2015.

31. Sheng JW, He M and Shi HC: A highly specific immunoassay for microcystin-LR detection based on a monoclonal antibody. Anal Chim Acta 603: 111-118, 2007.

32. Jin Z, Sun T, Xia X, Wei Q, Song Y, Han Q, Chen Q, Hu J and Zhang J: Optimized expression, purification of herpes B virus $\mathrm{gD}$ protein in escherichia coli, and production of its monoclonal antibodies. Jundishapur J Microbiol 9: e32183, 2016.

33. Aghebati Maleki L, Majidi J, Baradaran B, Abdolalizadeh J, Kazemi T, Aghebati Maleki A and Sineh Sepehr K: Large scale generation and characterization of anti-human CD34 monoclonal antibody in ascetic fluid of balb/c mice. Adv Pharm Bull 3: 211-216, 2013.

34. Yin W, Liu J, Zhang T, Li W, Liu W, Meng M, He F, Wan Y, Feng C, Wang S, et al: Preparation of monoclonal antibody for melamine and development of an indirect competitive ELISA for melamine detection in raw milk, milk powder, and animal feeds. J Agric Food Chem 58: 8152-8157, 2010.

35. Chen L, Wang L, Yan J, Ma C, Lu J, Chen G, Chen S, Su F, Wang W and Su X: 131I-labeled monoclonal antibody targeting neuropilin receptor type-2 for tumor SPECT imaging. Int J Oncol 50: 649-659, 2017.

36. Maragos CM, Busman M and Plattner RD: Development of monoclonal antibodies for the fusarin mycotoxins. Food Addit Contam Part A Chem Anal Control Expo Risk Assess 25: 105-114, 2008.

37. He Q, Cui X, Shen D, Chen Y, Jiang Z, Lv R, Eremin SA and Zhao S: Development of a simple, rapid and high-throughput fluorescence polarization immunoassay for glycocholic acid in human urine. J Pharm Biomed Anal 158: 431-437, 2018

38. Collazos J: Glycocholic acid in chronic active hepatitis and mild liver diseases. Clin Investig 72: 36-39, 1993.

39. Li T and Chiang JY: Bile Acid signaling in liver metabolism and diseases. J Lipids 2012: 754067, 2012.

40. Kim MJ and Suh DJ: Profiles of serum bile acids in liver diseases. Korean J Intern Med 1: 37-42, 1986.

41. Zhou L, Wang SB, Chen SG, Qu Q and Rui JA: Prognostic value of ALT, AST, and AAR in hepatocellular carcinoma with B-type hepatitis-associated cirrhosis after radical hepatectomy. Clin Lab 64: 1739-1747, 2018.

42. Stepien M, Fedirko V, Duarte-Salles T, Ferrari P, Freisling H, Trepo E, Trichopoulou A, Bamia C, Weiderpass E, Olsen A, et al: Prospective association of liver function biomarkers with development of hepatobiliary cancers. Cancer Epidemiol 40: 179-187, 2016.

43. Song WS, Park HM, Ha JM, Shin SG, Park HG, Kim J, Zhang T, Ahn DH, Kim SM, Yang YH, et al: Discovery of glycocholic acid and taurochenodeoxycholic acid as phenotypic biomarkers in cholangiocarcinoma. Sci Rep 8: 11088, 2018.

44. Collazos J, Mendarte U and De Miguel J: Clinical value of the determination of fasting glycocholic acid serum levels in patients with liver diseases. A comparison with standard liver tests. Gastroenterol Clin Biol 17: 79-82, 1993.

45. Li X, Yang L, Yang Y, Shao M and Liu Y: Preparation and characterization of a novel monoclonal antibody against the extracellular domain of human transferrin receptor. Monoclon Antib Immunodiagn Immunother 36: 1-7, 2017.

46. Han J, Qin WX, Li ZL, Xu AJ, Xing H, Wu H, Zhang H, Wang MD, Li C, Liang L, et al: Tissue and serum metabolite profiling reveals potential biomarkers of human hepatocellular carcinoma. Clin Chim Acta 488: 68-75, 2019.

47. Chen T, Xie G, Wang X, Fan J, Qiu Y, Zheng X, Qi X, Cao Y, Su M, Wang X, et al: Serum and urine metabolite profiling reveals potential biomarkers of human hepatocellular carcinoma. Mol Cell Proteomics 10: M110 004945, 2011.

48. Thjodleifsson B, Barnes S, Chitranukroh A, Billing BH and Sherlock S: Assessment of the plasma disappearance of cholyl'114C-glycine as a test of hepatocellular disease. Gut 18: 697-702, 1977 .

49. McCormick WC III, Bell CC Jr, Swell L and Vlahcevic ZR: Cholic acid synthesis as an index of the severity of liver disease in man. Gut 14: 895-902, 1973.

This work is licensed under a Creative Commons Attribution-NonCommercial-NoDerivatives 4.0 International (CC BY-NC-ND 4.0) License. 